\title{
Development of a Glia-Rich Axon-Sorting Zone in the Olfactory Pathway of the Moth Manduca sexta
}

\author{
Wolfgang Rössler, Lynne A. Oland, Mark R. Higgins, John G. Hildebrand, and Leslie P. Tolbert \\ ARL Division of Neurobiology, University of Arizona, Tucson, Arizona 85721-0077
}

Olfactory receptor cells (ORCs) of a particular odor tuning are dispersed in the olfactory epithelium, but their axons converge on distinct glomeruli in primary olfactory centers. As a consequence, axon associations must change to bring axons of ORCs with the same odor specificity together. Studies in Manduca sexta have indicated that just before they enter the antennal lobe (AL), ORC axons undergo extreme reorganization, finally entering the $A L$ in fascicles destined for subsets of glomeruli. This axon-sorting zone is heavily populated by glial cells, and ORC axon growth cones often are in close physical contact with the glia. In moths rendered glia deficient, ORC axons fail to fasciculate in this region. Using propidium iodide to label nuclei and 5-bromo-2' -deoxyuridine to monitor proliferation, we found that the glia in the sorting zone arise from the $A L$,

During development, axons of olfactory receptor cells (ORCs) face a pathfinding task different from that encountered by receptor axons in other sensory systems. In the visual, auditory, and somatosensory systems, neighboring sensory neurons project to neighboring areas in the CNS to form a more or less continuous topographical map. In contrast, axons of ORCs terminate within the primary olfactory centers in distinct neuropil structures, the glomeruli, which are organized in accordance not with the spatial distribution of the receptor cells in the sensory epithelium but instead with their olfactory responsiveness. In mice, for example, ORCs expressing mRNA for the same olfactory receptor protein are widely distributed over large areas within the olfactory epithelium. Their axons, however, project to one or two distinct glomeruli in the olfactory bulb (Vassar et al., 1994; Ressler et al., 1994; Mombaerts et al., 1996; Wang et al., 1998). In males of the moth Manduca sexta, pheromone-specific ORCs distributed along the antenna send axons to converge in individual glomeruli of the antennal lobe (AL) (Schneiderman, 1984; Christensen et al., 1995; Hildebrand, 1996; Rössler et al., 1999). In Drosophila melanogaster, ORCs expressing mRNA for the same putative olfactory receptor protein are localized in widely scattered sensilla (Clyne et al., 1999a,b; Vosshall et al., 1999). Thus the task for

Received July 2, 1999; revised Aug. 19, 1999; accepted Aug. 25, 1999.

This work was supported by National Institutes of Health Grants NS28495 and NS20040. We thank Patricia Jansma for technical assistance in the ARL Division's Microscopy Facility, and Nirav Merchant, Terrill Yuhas, and Wendy Pott for technical assistance in the Division's Image Analysis Facility. We are grateful to Dr. James Nardi (University of Illinois at Champaign-Urbana) for a generous gift of antibodies against Manduca fasciclin II and to Dr. A. A. Osman and Zenzele Mpofu for rearing Manduca sexta.

The contents of this paper are solely the responsibility of the authors and do not necessarily represent the official views of the National Institutes of Health.

Correspondence should be addressed to Dr. Wolfgang Rössler, ARL Division of Neurobiology, University of Arizona, P.O. Box 210077, Tucson, AZ 85721-0077. E-mail: roessler@neurobio.arizona.edu.

Copyright (C) 1999 Society for Neuroscience 0270-6474/99/199865-13\$05.00/0 appearing shortly after the first ORC axons arrive. Experimental removal of some or all of the sensory innervation revealed that proliferation of sorting-zone glia is triggered by ORC axons. A second set of glia arises in the antenna and migrates along the antennal nerve toward the brain, populating the nerve after the establishment of the sorting zone. Development of this type of glial cell is independent of contact of the ORC axons with their central targets. We conclude that the sorting zone arises from CNS glia in response to ingrowth of ORC axons, and a critical number of glia must be present in the sorting zone for axons to correctly establish new neighbor-neighbor associations.

Key words: antennal lobe; sensory mapping; cell-cell interactions; olfactory glomeruli; glial cells; cell birth
ORC axons growing toward their central targets is to shed topographical relations and establish new odor response-specific relationships before converging on specific glomeruli.

In mammals, ORC axons become sorted in the nerve layer of the olfactory bulb (Mombaerts et al., 1996; Whitesides and LaMantia, 1996), where they are surrounded by glial cells peculiar to the olfactory system (Doucette, 1984, 1989; Raisman, 1985; Marin-Padilla and Amieva, 1989; Valverde et al., 1992). Resorting of ORC axons has also been described at the interface between the olfactory nerve and the olfactory bulb in fish (Riddle and Oakley, 1991). In Manduca, ORC axons undergo a massive reorganization in a glia-rich region near the entrance of the antennal nerve (AN) into the AL (Oland et al., 1998a). In this sorting zone, parallel ingrowing ORC axons turn and intermingle to establish fascicles that project to individual glomeruli (Higgins et al., 1998). The sudden change in behavior of ORC axons in this region and their close association with glial processes (Oland et al., 1998b) suggest that the glial cells promote disassociation and/or sorting of ORC axons.

To learn more about mechanisms underlying the guidance and sorting of ORC axons, we investigated the distribution and proliferation patterns of glial cells in the peripheral olfactory nerve and in the sorting zone in Manduca. The length and accessibility of the ORC axon sorting zone in this species make it especially advantageous for observation of the cellular interactions involved in influencing axon behavior. Our findings suggest that future cellular and molecular studies should be aimed at elucidating the neuron-glia interactions that govern the sorting process and culminate in the formation of a chemotopic organization of olfactory glomeruli.

Parts of this study have been reported previously in abstract form (Higgins et al., 1998; Oland et al., 1999b). 
Figure 1. Reorganization of ORC axons in the sorting zone (SZ) at stage 5 of development. $A$, Two bundles of anterogradely labeled ORC axons (DiO; yellow-green) disassociate on entering the glia-rich (glial nuclei were labeled with propidium iodide; red) sorting zone and project to many areas in the antennal lobe $(A L)$. White arrows indicate glomeruli innervated by labeled ORC axons. $L C$, Lateral cell group of $A L$ neurons; $M C$, medial cell group of $A L$ neurons. Arrowhead indicates a fascicle of axons heading to a glomerulus. Large white arrow indicates the level of the cross section shown in $C$. $A N$, Antennal nerve. $B$, ORC axons that were labeled retrogradely by insertion of $\mathrm{DiO}$ crystals into the basal region of the sorting region (the position of the dye crystal is indicated by the black arrow) are distributed across the entire $A N$. The white arrows mark two glomeruli that are innervated by the labeled ORC axons; the arrowhead indicates the axon fascicle. $C$, Stereo image of a thick cross section of the basal portion of the sorting zone (approximately at the level indicated by white arrow in the frontal section in $A$ ) showing the high density of propidium iodide-labeled glial nuclei and suggesting that glial cells, at this level of the sorting zone, bundle axon fascicles as they leave the zone. $D, E$, ORC axons labeled with an antibody against Manduca fasciclin II (green) course in parallel in the antennal nerve (at right) and then change trajectory as they encounter propidium iodide-labeled glial cells of the sorting zone (red). Antennal lobe neuropil is just to the left of the area depicted in each micrograph. $D$, Control moth (stage 7); note that axons become fasciculated into thick MFas IIpositive fascicles (black arrows) and MFas II-negative bundles (unlabeled areas) as they emerge from the sorting zone. $E$, Moth treated with $\gamma$ radiation to reduce number of glial cells in sorting zone (stage 9); note that MFas II-positive axons still turn and intermingle in the glia-deficient sorting zone (white bracket) but emerge still intermixed with MFas II-negative axons. Scale bars: $A, B, D, 100 \mu \mathrm{m}$ (scale bar in $D$ is also valid for $E$ ); $C, 50 \mu \mathrm{m}$.
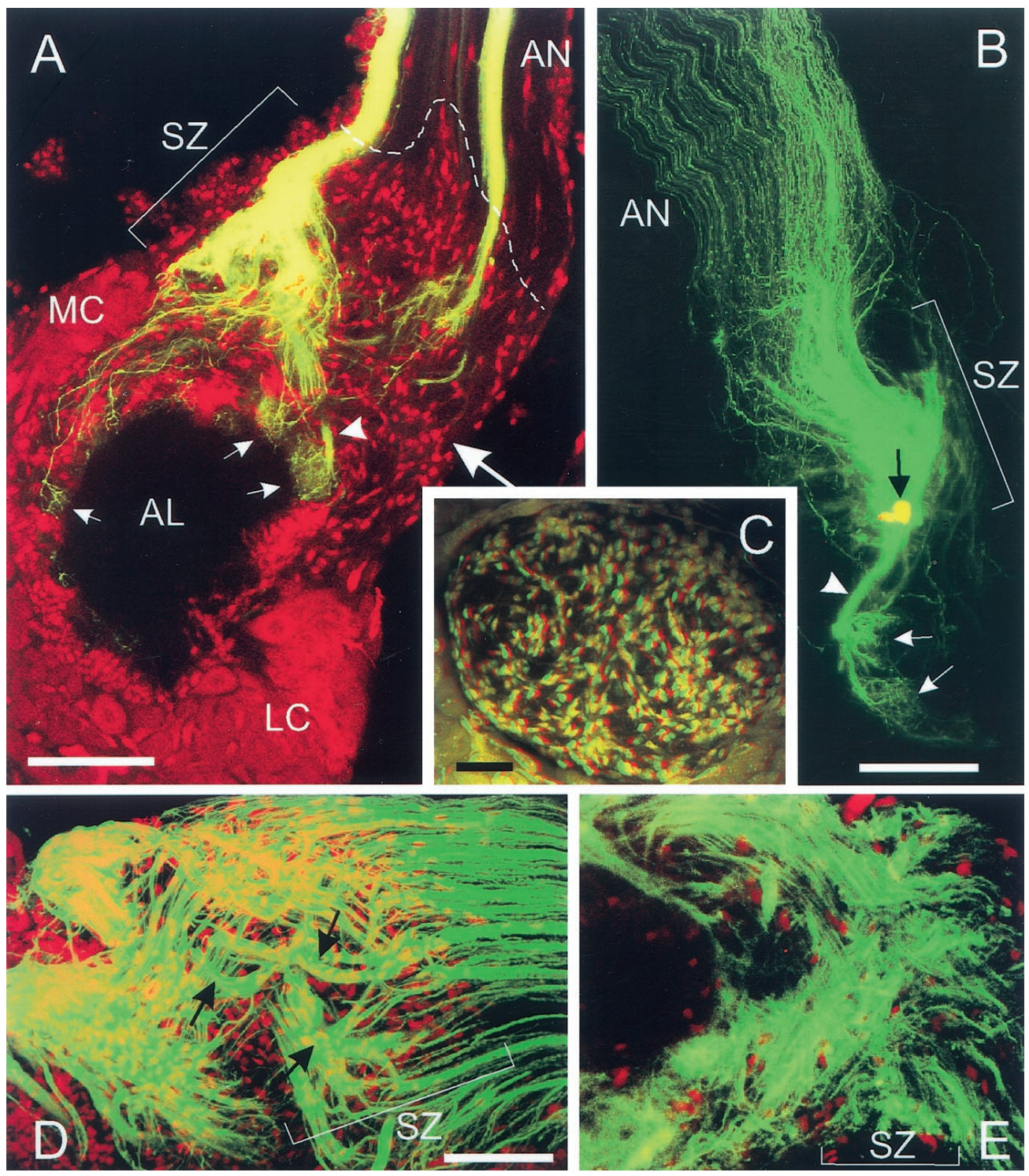

\section{MATERIALS AND METHODS}

Moths. Manduca sexta (Lepidoptera: Sphingidae) were reared from eggs in a laboratory colony at $26^{\circ} \mathrm{C}$ and $50-60 \%$ relative humidity under a long-day photoperiod regimen (17 hr light/7 hr dark), as described previously (Sanes and Hildebrand, 1976). Metamorphic adult development of Manduca proceeds through 18 stages, each lasting 1-4 d, beginning at the time of pupation and ending with the emergence of the adult moth. The developmental stages of metamorphosing moths were determined on the basis of criteria described by Tolbert et al. (1983) and Oland and Tolbert (1987). All experimental moths were anesthetized either by chilling on ice or by exposure to $\mathrm{CO}_{2}$.

Labeling of antennal olfactory receptor axons and glial cells. The nucleic acid stain propidium iodide was used to label glial cell nuclei in brains and in antenna preparations. For the antennal preparations, the developing antenna was filleted; that is, the antenna was cut open along the frontal midline, laid out, and secured with Minuten pins. Neuronal nuclei also were labeled, but because the cell bodies of neurons in the AL are larger and lie in spatially discrete clusters distinct from the position of the glial cells, the two cell classes were readily distinguished. After it was rinsed with PBS, pH 7.4, the tissue was treated with RNase [Sigma (St. Louis, MO) RNase R5503, $0.1 \mathrm{mg} / \mathrm{ml} \mathrm{PBS}$, $\mathrm{pH} 6.5$, for 10-15 min to reduce extranuclear RNA, washed in $\mathrm{PBS}$, and incubated in $25 \mu \mathrm{M}$ propidium iodide (P-1304, Molecular Probes, Eugene, OR) in PBS for 15 min. Thereafter, brains were washed in at least six changes of PBS, embedded in $7 \%$ low melting point agarose, sectioned at $100 \mu \mathrm{m}$ with a vibrating microtome (Vibratome, Technical Products International, St. Louis, MO), mounted in Hypaque meglumine 60\% (H582; Nycomed, Princeton, NJ), and viewed in a laser-scanning confocal microscope (see below). Antennal preparations were dehydrated in an ascending ethanol series, cleared in methyl salicylate, and mounted on slides as whole mounts. With the RNase treatment used here, nuclei became brightly stained, and the major processes of glial cells (but not neurons) exhibited light staining attributable to their complement of ribosomes (Tolbert and Hildebrand, 1981; Baumann et al., 1996; Oland et al., 1999a).

Sensory axons of the AN were mass-labeled with the lipophilic dye 3,3'-dioctadecyloxacarbocyanine perchlorate (DiO) [Molecular Probes; method described in more detail by Baumann et al. (1996) and Rössler et al. (1998)]. After dissection and desheathing, the brains were fixed in a solution containing $4 \%$ paraformaldehyde and $0.15 \%$ glutaraldehyde in $0.1 \mathrm{M}$ phosphate buffer, $\mathrm{pH} 7.4$, for $\sim 24 \mathrm{hr}$. A few small crystals of DiO, manipulated with Minuten pins, were inserted into the AN. After application of the dye, the brains were transferred back into the fixative solution for a period of 3-7 d at room temperature to allow the dye to diff use. The brains then were rinsed in PBS and processed in most cases 

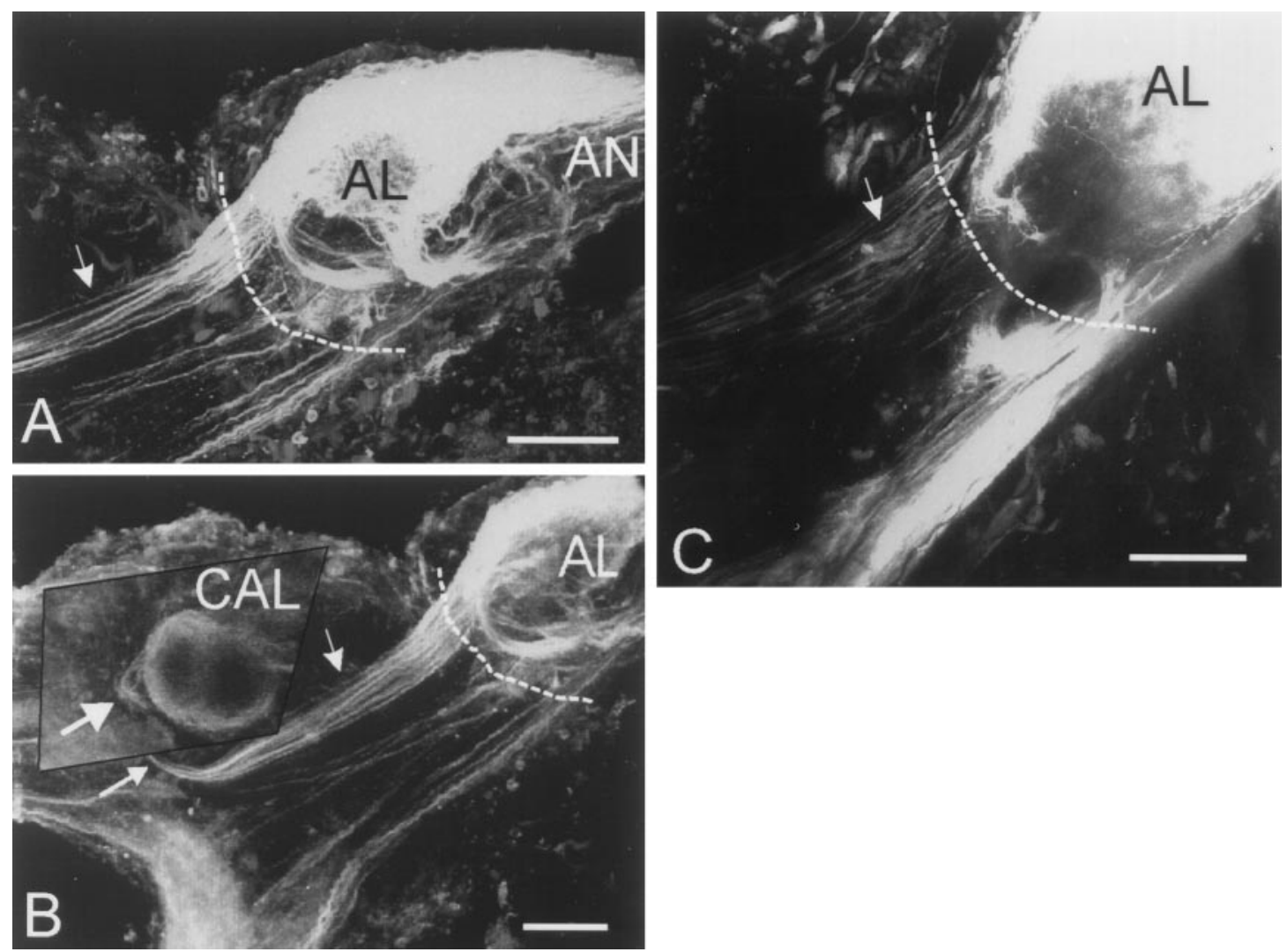

Figure 2. In glia-deficient moths, many ORC axons overshoot the antennal lobe and project to abnormal targets. $A, B$, Axons labeled with antibody to MFas II enter the antennal lobe $(A L)$ via the antennal nerve $(A N)$ (stage 9). Although in normal moths all MFas II-positive ORC axons terminate in the AL, in this moth many MFas II-positive axons course beyond the AL (white arrow indicates one of several abnormal tracts). In $B$, one set of these axons can be seen to have terminal branches in the calyces $(C A L)$ of the mushroom bodies, which are normally important targets of AL output neurons. White arrows mark a fascicle of axons in two different focal planes. $C$, Axons labeled by DiO application to the AN show the same pattern of projection as MFas II-labeled axons (white arrow), indicating that these are indeed ORC axons from the AN (stage 9). The dashed lines in $A-C$ indicate the approximate outline of the normal AL border. Scale bars: $A, B, 100 \mu \mathrm{m}: C, 50 \mu \mathrm{m}$.

in RNase and propidium iodide (as above) to label glial cell nuclei. The brains subsequently were prepared as above for confocal microscopy.

Fasciclin-II immunocytochemistry. Antibody to Manduca fasciclin II (MFas II) was generously supplied by Dr. James B. Nardi (University of Illinois). The polyclonal antibody (PAb2F5) was derived from mouse after four immunizations with the $91 \mathrm{kDa}$ component of antigen $2 \mathrm{~F} 5$ (Nardi, 1992). Using an immunoaffinity column and electroelution from SDS nonreducing polyacrylamide gels, Nardi (1992) was able to purify this antigen, and after determining its amino acid sequence he found that one of its peptides had 61.5 and $77 \%$ identity to fasciclin II of Drosophila and grasshopper, respectively.

Whole brains of various developmental stages were dissected and fixed overnight in $4 \%$ paraformaldehyde in $0.1 \mathrm{M}$ phosphate buffer, $\mathrm{pH} 7.4$, at $4^{\circ} \mathrm{C}$. Brains were then washed in PBS and processed as follows, either as whole brains or as sections. Sections were prepared by embedding in 7\% low melting point agarose (Life Technologies, Gaithersburg, MD) and sectioning on a Vibratome at $100 \mu \mathrm{m}$. Tissue was then washed in PBS containing $1 \%$ Triton X-100 (PBST), and nonspecific binding was blocked with $4 \%$ normal goat serum (NGS; Life Technologies) in PBST at room temperature for $1 \mathrm{hr}$. Tissue was then incubated overnight at $4^{\circ} \mathrm{C}$ with PAb2F5 (1:1000) diluted in 4\% NGS/PBS. Primary antibody was washed off with PBS, and CY5-conjugated goat anti-mouse secondary antibody (Jackson ImmunoResearch, West Grove, PA) was applied at a dilution of 1:100 for $2 \mathrm{hr}$ at room temperature. This was washed off with PBS, and whole brains were dehydrated in a series of ethanols, cleared, and mounted in methyl salicylate; sections were mounted on slides in polyvinyl alcohol.

Bromodeoxyuridine injection and immunocytochemistry. Glial cell proliferation was assessed by monitoring DNA synthesis by means of incorporation of 5-bromo-2'-deoxyuridine (BrdU; Sigma B-9285) as a marker (Gratzner, 1982). BrdU solution (100 $\mu \mathrm{l}$ of a $50 \mu \mathrm{g} / \mathrm{ml}$ aqueous solution) was injected through the wing cuticle into the hemolymph. The injection site was sealed with paraffin, and the moths were returned to controlled conditions as described above. After $18 \mathrm{hr}$ the moths were anesthetized, and the brains or antennae were dissected free from the surrounding tissue. For visualization of BrdU incorporation, standard immunohistochemical techniques were used. Brains or antennae were fixed overnight in $4 \%$ paraformaldehyde solution in $0.1 \mathrm{M}$ phosphate buffer and then rinsed three times (15 min each) in PBS, processed as whole mounts or embedded in $7 \%$ low melting point agarose, and serially sectioned in the frontal plane with a Vibratome at $100 \mu \mathrm{m}$ thickness. Sections were subsequently incubated for $30 \mathrm{~min}$ in $2 \mathrm{~N} \mathrm{HCl}$ in PBS to denature DNA, facilitating recognition of BrdU by the antibody. After three rinses (15 min each) in $\mathrm{PBS} / 0.3 \%$ Triton $\mathrm{X}-100$ to restore the $\mathrm{pH}$ to 7.3 , the sections were incubated for $45 \mathrm{~min}$ in $3 \%$ NGS (no. 16210-015, Life Technologies) in PBS $/ 0.3 \%$ Triton X-100. Sections were incubated for $2 \mathrm{~d}$ at $4^{\circ} \mathrm{C}$ in a mouse anti-BrdU antibody (no. 347580, Becton Dickinson, San Jose, CA), diluted 1:200 in PBS/0.3\% Triton X-100 with $1 \%$ NGS. This was followed by five rinses of $10 \mathrm{~min}$ each in PBS and a $2 \mathrm{hr}$ incubation in goat anti-mouse Cy3-conjugated secondary antibody (no. 115-165-062, Jackson ImmunoResearch; diluted 1:100 in PBS). After five washes of $10 \mathrm{~min}$ each in PBS, sections were mounted on slides in Hypaque meglumine $60 \%$ or dehydrated in a graded ethanol series, mounted in methyl salicylate, and viewed with the confocal microscope.

Removal of afferent input and surgical removal of the brain. To study the influence of sensory axons on the development of glia in the sorting zone, we partially or completely removed antennal afferent input. During stage 1 of metamorphic adult development $(\sim 10-20 \mathrm{hr}$ after pupation), before ORCs are born in the antenna (Sanes and Hildebrand, 1976), the cuticle overlying the base of the developing antenna was opened to form a window. The underlying antennal tissue was scraped away and removed, and the cuticular window was closed and sealed with melted paraffin [for 

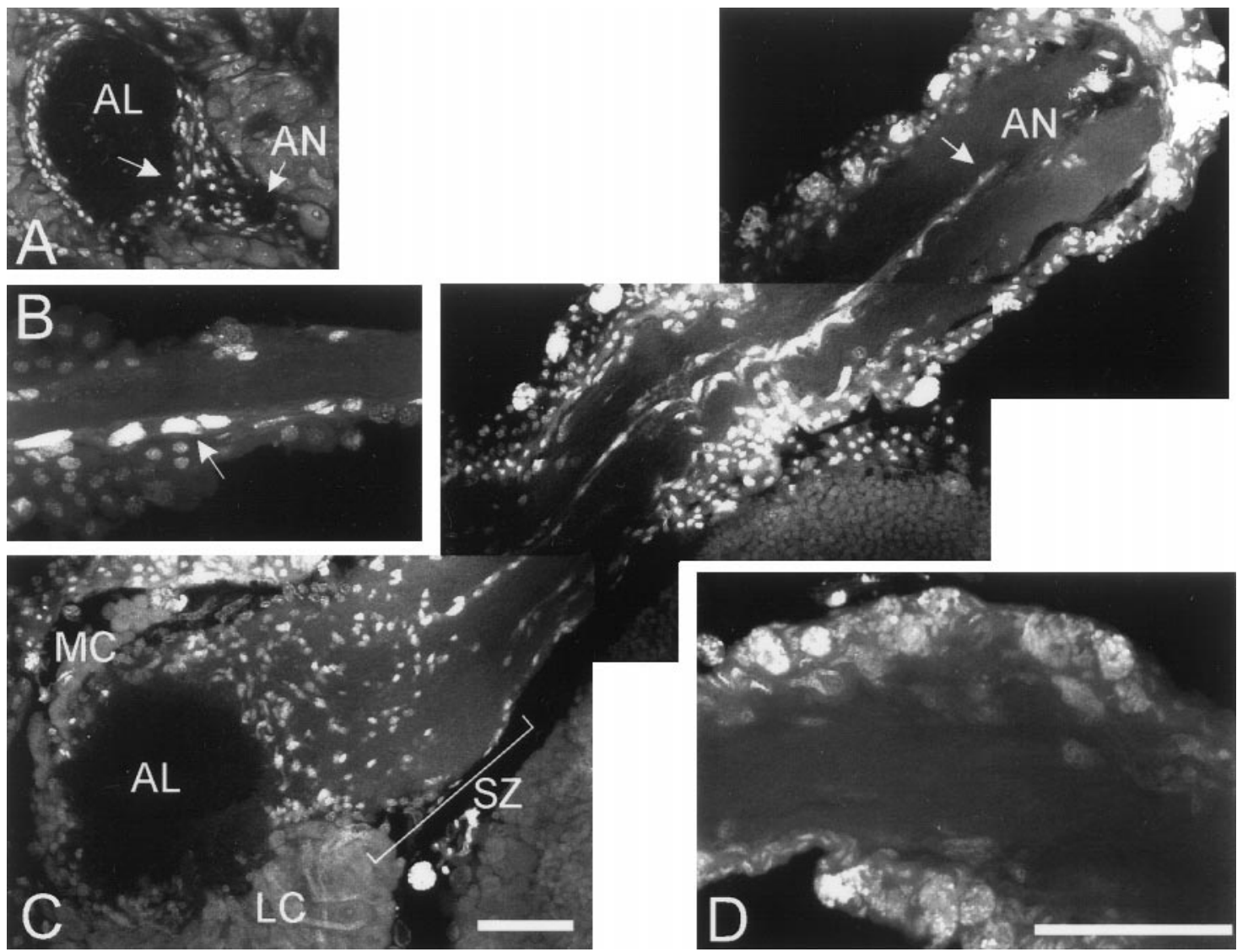

Figure 3. Development of glial cells in the sorting zone $(S Z)$ and the intracranial portion of the antennal nerve $(A N)$ : stages 3 and 5. $A$, Antennal lobe $(A L)$ at stage 3 showing the beginning development of the sorting zone as an accumulation of glial cells (labeled with propidium iodide) in the entrance region of the AN (white arrows). B, Higher magnification of the intracranial portion of the AN at stage 3. The perineurial sheath of the nerve contains cells with large nuclei (arrow), but the nerve itself is devoid of glial cells. $C$, Antennal lobe and intracranial portion of the $A N$ at early stage 5. Glial cells (propidium iodide-labeled glial nuclei are visible) have populated the sorting zone, and a line of midline glial cells (white arrow) has formed in the proximal $A N$. $D$, Higher magnification of one of the two branches of the $A N$ showing that this portion of the $A N$ remains devoid of glial cells at this stage. $L C$, Lateral cell group of $A L$ neurons; $M C$, medial cell group of $A L$ neurons. Scale bars: shown in $C$ for $A$ and $C, 50 \mu \mathrm{m}$; shown in $D$ for $B$ and $D, 50 \mu \mathrm{m}$.

more details see Tolbert and Sirianni (1990)]. For partial deantennation, the basal five annuli (subsegments) of the antennal flagellum were left intact. The number of antennal annuli that developed on each side was determined before brain dissection. It should be noted that complete deantennation removes most of the sensory input to the AL but leaves a small input from the labial pit organ (Kent et al., 1986), which projects to a single glomerulus at the ventral pole of the AL.

To study the development of glia in the AN in the absence of the central target, the brain was removed at late pupal stage 2 , before the first ingrowing ORC axons from the developing antenna reach the $\mathrm{AL}$ (Oland et al., 1998a). A small window was cut in the dorsal head cuticle, and the brain was cut free and removed with fine scissors and forceps. To avoid trapping air in the head of the pupa, lost hemolymph was replaced by adding TES-saline $\left[0.15 \mathrm{M} \mathrm{NaCl}, 0.003 \mathrm{M} \mathrm{KCl}, 0.003 \mathrm{M} \mathrm{CaCl}_{2}, 0.01 \mathrm{M}\right.$ $n$-tris(hydroxymethyl)methyl-2-aminoethane-sulfonic acid (TES; Sigma), $0.025 \mathrm{M}$ sucrose, adjusted to $\mathrm{pH}$ 6.9] with $15 \mathrm{mg} / 1$ of 1-phenyl-2-thiourea (PTU; Sigma). The cuticular window was closed and sealed with paraffin, and the moths were returned to controlled conditions to continue development.

Generation of glia-deficient preparations. Manduca were exposed to gamma radiation from a ${ }^{60} \mathrm{Co}$ source (Pheratron 80, Atomic Energy of Canada Ltd.), using an irradiation protocol established in a previous study (Oland et al., 1990). Briefly, moths received whole-body radiation at a total dose of $750 \mathrm{~Gy}$ given in two equal fractions, the first during stage 4 and the second $24 \mathrm{hr}$ (less than one developmental stage) later. The timing of the irradiation was chosen for several reasons: glial cells are dividing (Oland and Tolbert, 1989; Kirschenbaum et al., 1995), neurons in the antenna and the AL are post-mitotic (Sanes and Hilde- brand, 1976; Oland and Tolbert, 1989), ORC axons have just begun to grow into the AL (Sanes and Hildebrand, 1976; Oland et al., 1998a), and glomeruli have not yet formed (Oland and Tolbert, 1996).

Laser-scanning confocal microscopy and electron microscopy. Specimens were viewed with a laser-scanning confocal microscope (Bio-Rad MRC600, Cambridge, MA), equipped with a Nikon Optiphot-2 microscope and both $15 \mathrm{~mW}$ krypton/argon and $100 \mathrm{~mW}$ argon laser light sources, using appropriate filter combinations. Serial optical sections were imaged at intervals of $2-5 \mu \mathrm{m}$ through the depth of the sections (or tissue in the case of whole-mounted preparations) and saved as three-dimensional stacks. Two-dimensional projections were generated for each channel and merged with the use of different pseudocolors. Where needed, the digitized images were modified only to enhance contrast, to merge images from consecutive sections of the same preparation, or to form montages of images from adjacent regions. Image processing and labeling of figures were performed with one or more of the following programs: Confocal Assistant (copyrighted by Todd Brelje, distributed by Bio-Rad), Corel Photopaint, and Corel Draw (Corel Corporation, Ottawa, Ontario, Canada).

For electron microscopy, the brains and nerves were rapidly dissected and immersed in cold fixative solution containing $2.5 \%$ glutaraldehyde, $0.5 \%$ paraformaldehyde, $0.18 \mathrm{M} \mathrm{CaCl}_{2}, 0.58 \mathrm{~mm}$ sucrose, and $0.1 \mathrm{M}$ sodium cacodylate buffer (Tolbert and Hildebrand, 1981). After secondary fixation in $1 \% \mathrm{OsO}_{4}$, followed by staining in $1 \%$ uranyl acetate in $70 \%$ ethanol and dehydration through graded ethanols, preparations were embedded in Epon/Araldite. Sections $(1 \mu \mathrm{m})$ were stained with toluidine blue; thin sections for electron microscopy were stained with lead citrate and examined in a JEOL JEM-1200EX electron microscope. 


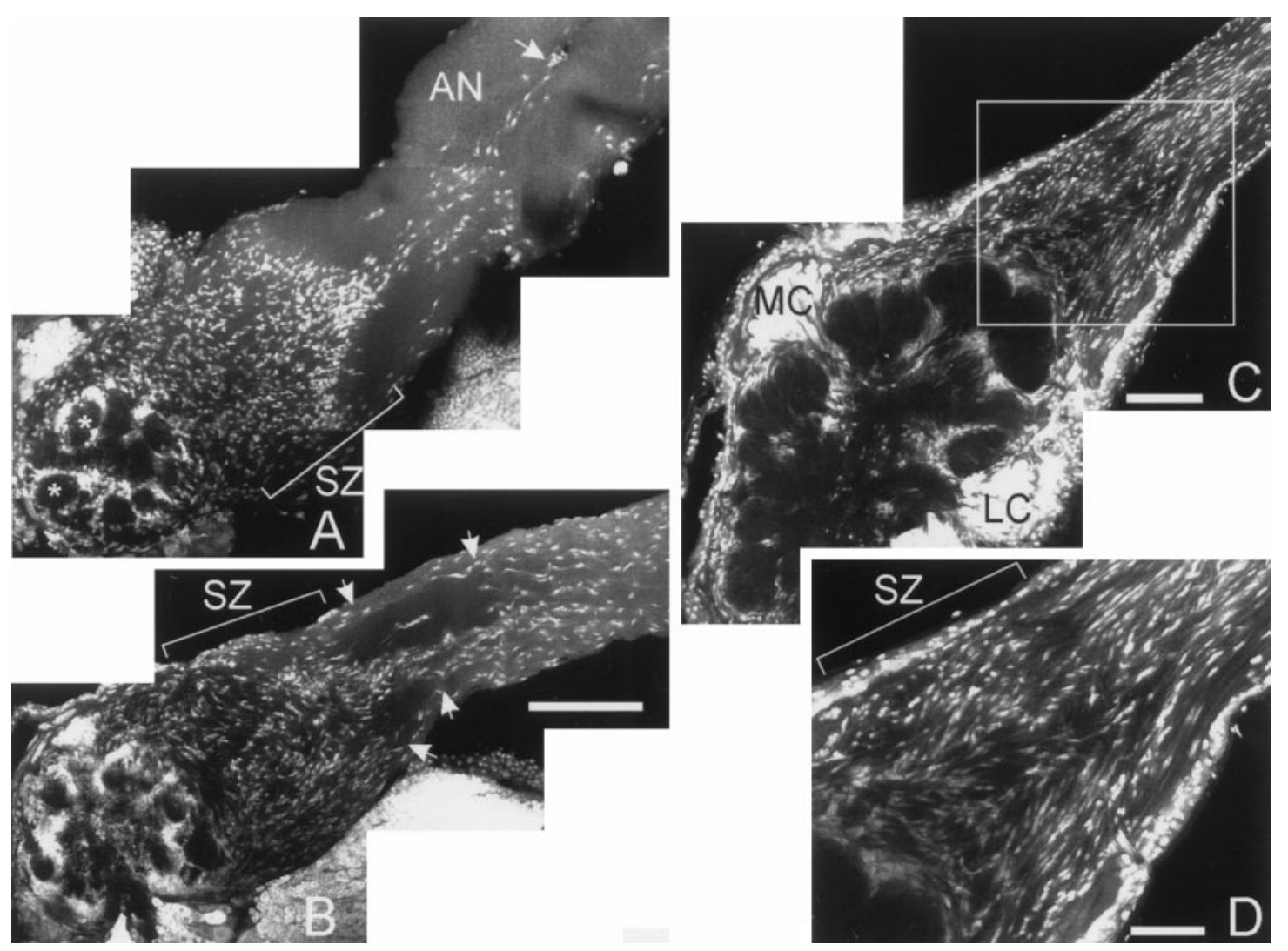

Figure 4. Development of glial cells in the sorting zone $(S Z)$ and the intracranial portion of the antennal nerve $(A N)$ : stages 6, 7, and adult. $A$, At stage 6 , the sorting zone is heavily populated with glial cells (propidium iodide-labeled glial nuclei are visible), and a band of glial cells extends along the midline of the proximal AN (arrow). The asterisks indicate glomeruli, which are surrounded by glial borders. $B$, At stage 7, the intracranial distal portion of the $A N$ begins to fill with glial cells. Arrows indicate a gap between the glia of the sorting zone and the peripheral portion of the AN. $C$, Adult female $A L$ and $A N$. Glial cells occupy the entire length of the $A N$. $D$. Higher magnification of the boxed area in $C$ showing the sorting zone in the adult $A N$. In the $A N$ (to the right of the sorting zone), glial cells are oriented parallel to the long axis of the nerve, whereas in the sorting zone, glial cells are not oriented in any preferential direction. $L C$, Lateral cell group of $A L$ neurons; $M C$, medial cell group of $A L$ neurons. Scale bars: shown in $B$ for $A$ and $B, 100 \mu \mathrm{m} ; C, 100 \mu \mathrm{m} ; D, 50 \mu \mathrm{m}$.

\section{RESULTS}

Reorganization of antennal ORC axons in the region where the AN enters the AL becomes evident soon after the ingrowth of the first ORC axons, which reach the AL neuropil late in stage 3 (Oland and Tolbert, 1996; Oland et al., 1998a). By stage 5 of the 18 stages of metamorphic adult development, ORC axons have reached most target areas within the AL. In the AN, ORC axons that traveled in parallel or in close proximity may abruptly change their course on entrance into the glia-rich sorting zone (Fig. 1). Local application of small crystals of the lipophilic marker DiO in two places of the peripheral portion of the AN at stage 5 resulted in labeling of two bundles of ORC axons traveling in parallel within the AN (Fig. 1A). Axons within the two bundles in the example shown in Figure $1 A$ remained bundled until they reached the sorting zone, where individual ORC axons or small bundles of axons coursed in many directions. After passing the sorting zone, ORC axons traveled in bundles that eventually entered individual developing glomeruli in many areas of the AL. After application of small DiO crystals to the basal portion of the sorting zone, where axons emerge in fascicles to enter the AL, retrogradely labeled ORC axons were distributed across the entire diameter of the AN (Fig. $1 B$ ), whereas anterogradely labeled ORC axons formed distinct bundles within the AL, heading for a small subset of glomeruli (Fig. $1 B$, white arrows). Taken together, these results indicate that neighboring axons in the AN can disperse to innervate widely separated glomeruli within the AL, whereas axons dispersed in the $\mathrm{AN}$ can converge on a small number of glomeruli. A cross section through the basal portion of the sorting zone illustrates the high density of glial cells in this area, which in this region surround emerging fascicles of axons (Fig. 1C).

\section{Behavior of axons of olfactory receptor cells in the sorting zone of glia-deficient moths}

To determine whether glial cells in the sorting zone influence the behavior of ORCs, we used irradiation to reduce severely the number of glial cells present during early stages of axon growth into the AL. In one preparation, we roughly estimated the number of glial cells in the sorting zone and found the number to be approximately one-quarter of that found in a normal sorting zone at the same stage. This degree of reduction is comparable to that achieved with neuropil-associated glial cells in our earlier studies of the effect of those glia cells on glomerulus formation (Oland et al., 1990).

The behavior of axons in glia-deficient preparations was assessed either by labeling the specific subset of ORC axons that express fasciclin II or by staining a general subset of AN axons with DiO. In the normal sorting zone, ORC axons disassociate from neighbors, change their trajectories, and eventually leave the zone in fascicles. This behavior is particularly obvious in MFas 

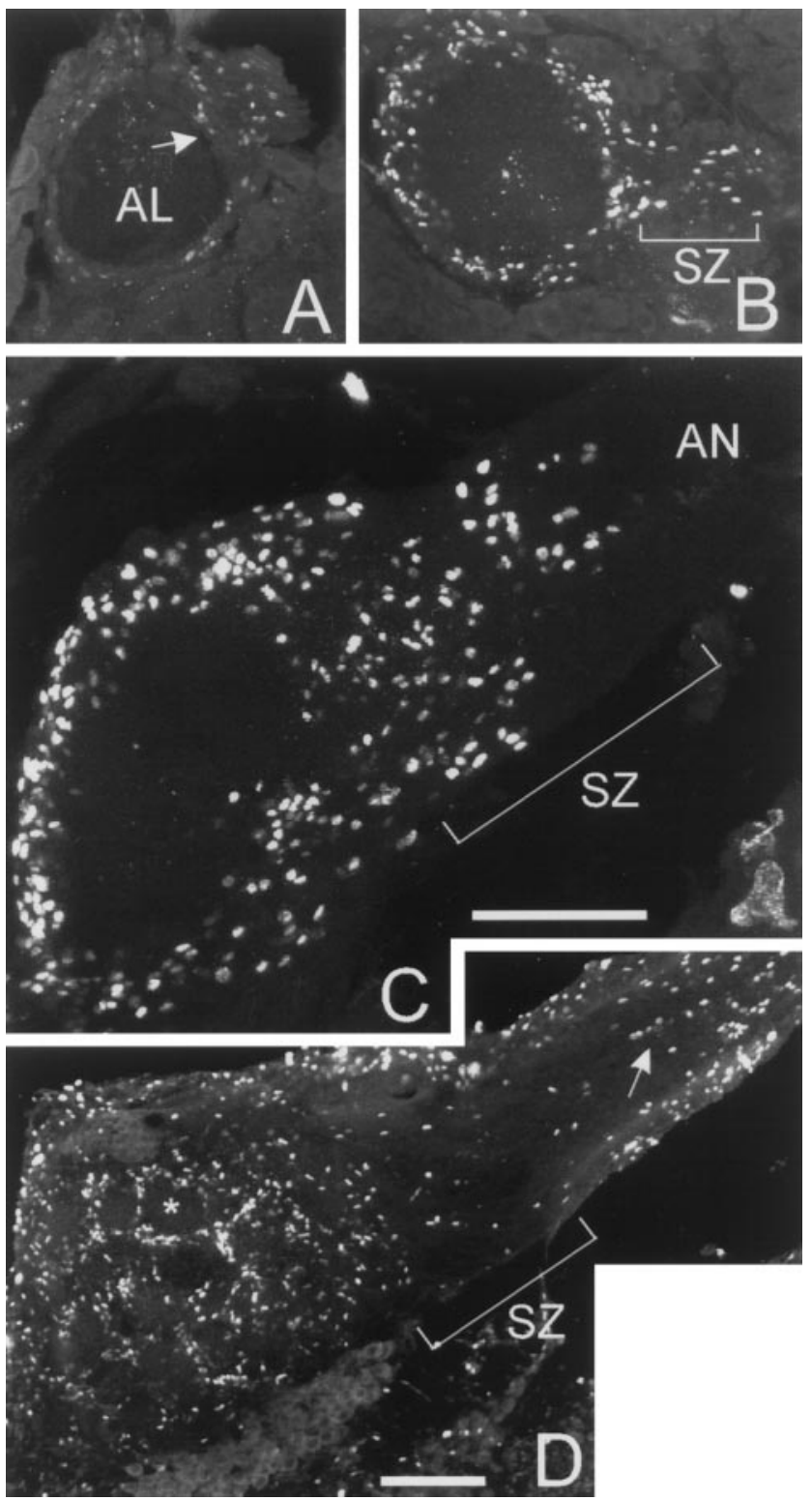

Figure 5. Proliferation of glial cells in the antennal lobe $(A L)$, the sorting zone $(S Z)$, and the intracranial portion of the antennal nerve $(A N)$. Glial nuclei labeled with BrdU immunocytochemistry. $A$, Stage 3 . The white arrow indicates the entrance region of the AN. B, Stage 4. C, Stage 5. D, Stage 7. The asterisk indicates a glomerulus. Arrow indicates BrdU-labeled glial nuclei in the peripheral portion of the $A N$. Scale bars: shown in $C$ for $A-C, 100 \mu \mathrm{m} ; D, 100 \mu \mathrm{m}$.

$\mathrm{II}^{+}$axons (Fig. 1D), which are distributed throughout the body of the AN until they reach the sorting zone. On leaving the sorting zone, they are bundled in relatively large fascicles and traverse in the nerve layer to a specific subset of glomeruli (Higgins et al., 1998). In a glia-deficient sorting zone, MFas $\mathrm{II}^{+}$axons changed trajectories but left the sorting zone without forming obvious fascicles with other MFas $\mathrm{II}^{+}$axons, suggesting that they failed to find like axons as they coursed through the zone (Fig. 1E). In addition, once in the AL, many of the MFas $\mathrm{II}^{+}$axons failed to find their target glomeruli and instead continued past the AL (Fig. 2A,B), some along a tract followed by antennal mechanosensory axons and some along an established olfactory output tract to the protocerebrum. The fact that not all antennal axons grew past the AL could indicate that ORC axons are not uniformly influenced by the sorting-zone glia. Although the failure of many axons to find their glomerular targets may be a result of failure to fasciculate properly, we cannot exclude the possibility that targeting failure within the AL was a result of loss of neuropil-associated glial cells in the AL, because the method of irradiation reduces the number of glia in the $\mathrm{AL}$ as well as in the nerve.

To be certain that the MFas $\mathrm{II}^{+}$axons that extended beyond the AL were indeed primary-afferent axons from the AN (and not, for instance, axons of AL projection neurons abnormally expressing MFas II), we labeled axons by placing DiO crystals in the ANs of a group of glia-deficient moths. The pattern made by the DiO-labeled axons was essentially identical to that of the MFas $\mathrm{II}^{+}$axons (Fig. 2C) and differed from the pattern in normal moths, where ORC axons at these stages always terminate in the AL (Oland et al., 1990, 1998).

\section{Development of the glial-cell population in the sorting zone and intracranial portion of the antennal nerve}

If the sorting zone is important in ensuring the correct sorting of ORC axons, then it must be present from the time at which the first axons approach but have not yet entered the AL, i.e., from early in stage 3 of metamorphic adult development. We followed the rise of the sorting zone glial population by labeling glial nuclei with propidium iodide and by monitoring their proliferation with BrdU immunocytochemistry.

At stage 2, the AL neuropil is surrounded by a thin shell of glial cells, with no obvious differences in thickness across the AL. At stage 3 (Fig. $3 A$ ), when ORC axons begin to enter the AL, a small accumulation of glial cells appears just outside the lateral edge of the glial shell. At this stage, the AN is surrounded by a perineurial sheath made up of two layers of cells with differently shaped and relatively large nuclei, but the $\mathrm{AN}$ itself does not contain glial cells (Fig. 3B). By early stage 5, the diameter of the AN has increased significantly, and glial cells have populated the developing sorting zone (Fig. $3 C$ ). In addition, a line of glial cells has formed along the middle of the proximal portion of the AN. At stage 5 the line extends outward to the point where the AN divides into the two peripheral branches that arise in the antenna. ORC axons do not appear to cross this central line of glia. The glial cells rather appear to mark the separation of the two nerve branches until they reach the sorting zone. Higher magnification of one of the two branches of the AN at a more distal location at this stage shows that the intracranial portion of the AN remains devoid of glial cells (Fig. 3D). By stage 6, the number and density of glial cells in the sorting zone have significantly increased, and the midline glia remain (Fig. $4 A$ ). A few glial cells appear, for the first time, in other regions of the peripheral AN. At stage 7, the peripheral AN contains many glial cells in the body of the nerve (Fig. $4 B$ ). In the example shown, a small gap (Fig. 4B, arrows) can still be seen between the glial populations in the peripheral AN and in the sorting zone, except for the glial cells along the middle and in the perineurial sheath. In the adult, the entire AN is heavily populated with glial cells whose elongated nuclei are oriented parallel with the ORC axons (Fig. $4 C, D$ ). In the sorting zone, there is no preferred orientation of nuclei or cell processes (Fig. 4D). Examination at the electron microscopic level did not reveal any significant ultrastructural differences that would allow distinction among glial cell populations in the peripheral AN, in the sorting region, or associated with the AL neuropil (data not shown). 

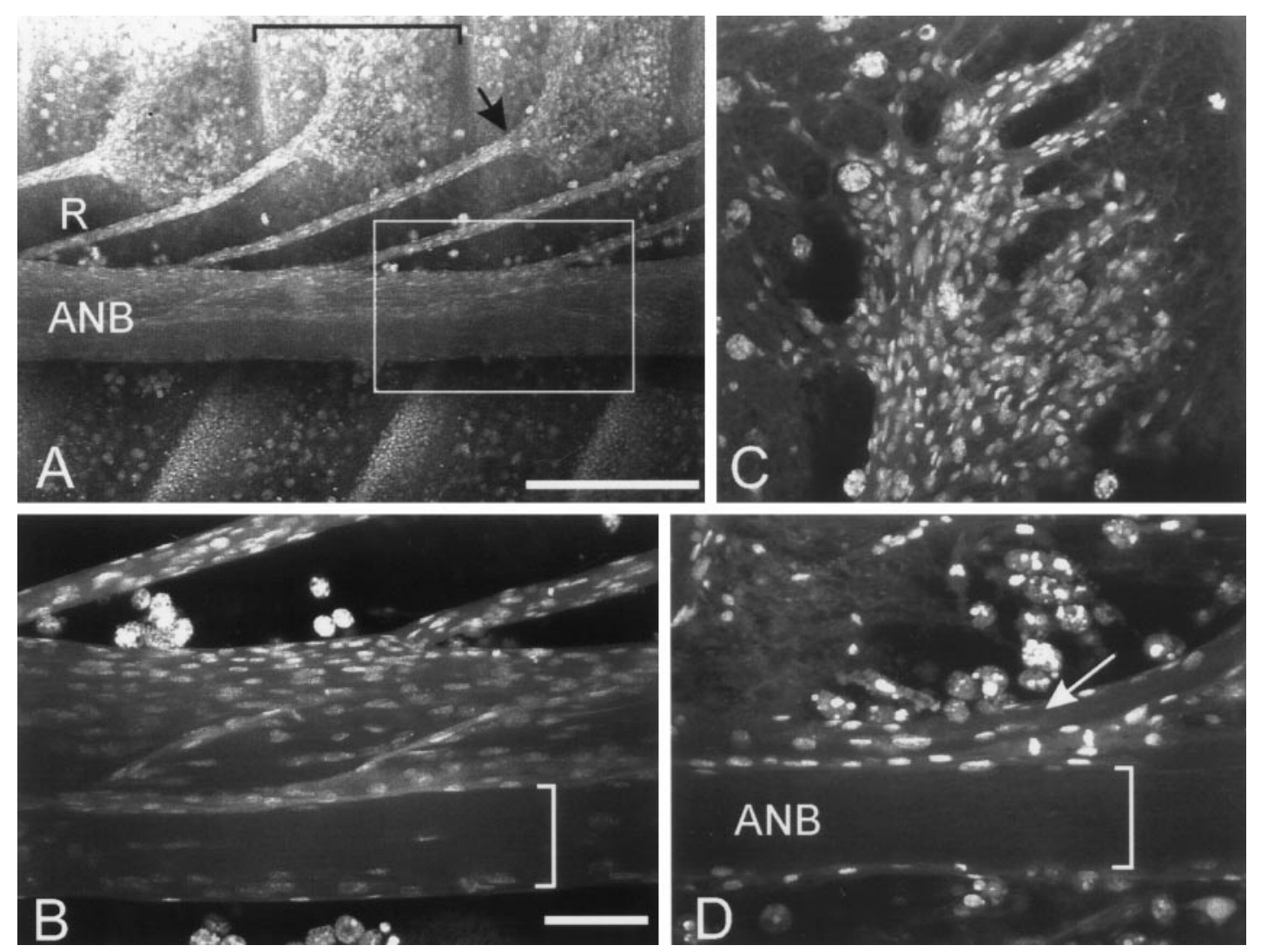

Figure 6. Development of glial cells in the peripheral antennal nerve within the antenna. $A$, Half of the antenna at stage 5 showing three hemisegments (the one in the middle is indicated by the bracket) of the antenna and the ipsilateral branch of the two antennal nerve branches $(A N B)$ within the antenna. In each hemisegment, receptor axons converge into a nerve rootlet ( $R$; large black arrow) that joins the ipsilateral nerve branch. $B$, Higher magnification of the boxed area in $A$ showing the antennal nerve branch and two rootlets joining the nerve. The rootlets contain numerous propidium iodide-labeled glial nuclei, and the nerve branch contains glial cells preferentially located on the side where the rootlets join the main nerve. The portion of the nerve branch that lacks glial cells is indicated by the white bracket. $C$. Higher magnification of the sensory nerves in the antennal epithelium. Note the high density of glial cells in this area. $D$, One of the two branches of the antennal nerve in a filleted antenna at stage 3 with one nerve rootlet joining the nerve branch (white arrow). The nerve rootlet contains a few glial cells (white arrow), but the nerve branch (bracket) does not contain glial cells except for the perineurial sheath. Scale bars: $A, 100 \mu \mathrm{m}$; shown in $B$ for $B-D, 50 \mu \mathrm{m}$.

Incorporation of BrdU was used to monitor proliferation of glial cells in the sorting zone (Fig. 5) and to compare the temporal patterns of proliferation among glia in the different regions of the olfactory axon pathway. At stage 3 (Fig. $5 A$ ), BrdU-containing nuclei were found in glial cells surrounding the AL neuropil and in glial cells located in the entrance region of the AN. At stage 4, the number of labeled nuclei surrounding the AL neuropil and in the sorting zone had increased (Fig. $5 B$ ). At stage 5, both the AL and the sorting zone contained many labeled cells (Fig. $5 C$ ). The intracranial portions of the ANs lacked BrdU-labeled cells at stages 3, 4, or 5. Labeling decreased in the sorting zone during stage 6 (data not shown) and by stage 7 had almost disappeared, but at stage 7, BrdU-labeled glial cells appeared for the first time in the peripheral AN (Fig. 5D, arrow).

That proliferation within the sorting zone begins just after the first ORC axons approach the AL suggests that these axons might trigger the glial proliferation that generates the sorting zone glial population, a hypothesis that we test below.

\section{Development of glial cells in the peripheral antennal nerve}

To determine the source and pattern of glial cells in the part of the AN within the antenna, we used a filleted preparation of the antenna. The developing antenna was labeled with either propidium iodide (Fig. 6) or BrdU (Fig. 7).
Each hemisegment of the antennal flagellum gives rise to a sensory nerve rootlet that joins the ipsilateral branch of the AN within the antenna (Fig. 6A). At stage 3, only the nerve rootlets contained glial cells. The AN branches were not yet populated by glial cells (except for the perineurial sheath) (Fig. 6D), and proliferating glial cells were found only in the sensory epithelium and the nerve rootlets (Fig. 7A,D). By stage 4, the AN branches were filled with glial nuclei that had taken up BrdU, and many glial cells in the epithelium also were labeled (Fig. 7B,E). At stage 5 , glial cells were present in the antennal nerve branches, in the nerve rootlets, and in the area where the sensory nerve rootlets branch out in the antennal epithelium (Fig. 6A-C). The AN branches contained significantly more glial cells on the sides where the nerve rootlets enter the nerves (Fig. 6B). At this stage, examination of the AN at the electron microscopic level (data not shown) showed the AN branches to be roughly subdivided into two parts: one, lying adjacent to the epithelium, in which glial cell processes enwrap axon fascicles associated with rootlets, and another, facing the lumen of the antenna, in which thousands of axons from more peripheral segments are bundled together without glial cells. A small number of relatively large axons (average diameter $0.6 \mu \mathrm{m}$ ) embedded in the mass of ORC axons may be axons of the pupal nerve that extends from the antenna to the brain from the beginning of metamorphic development or may be 

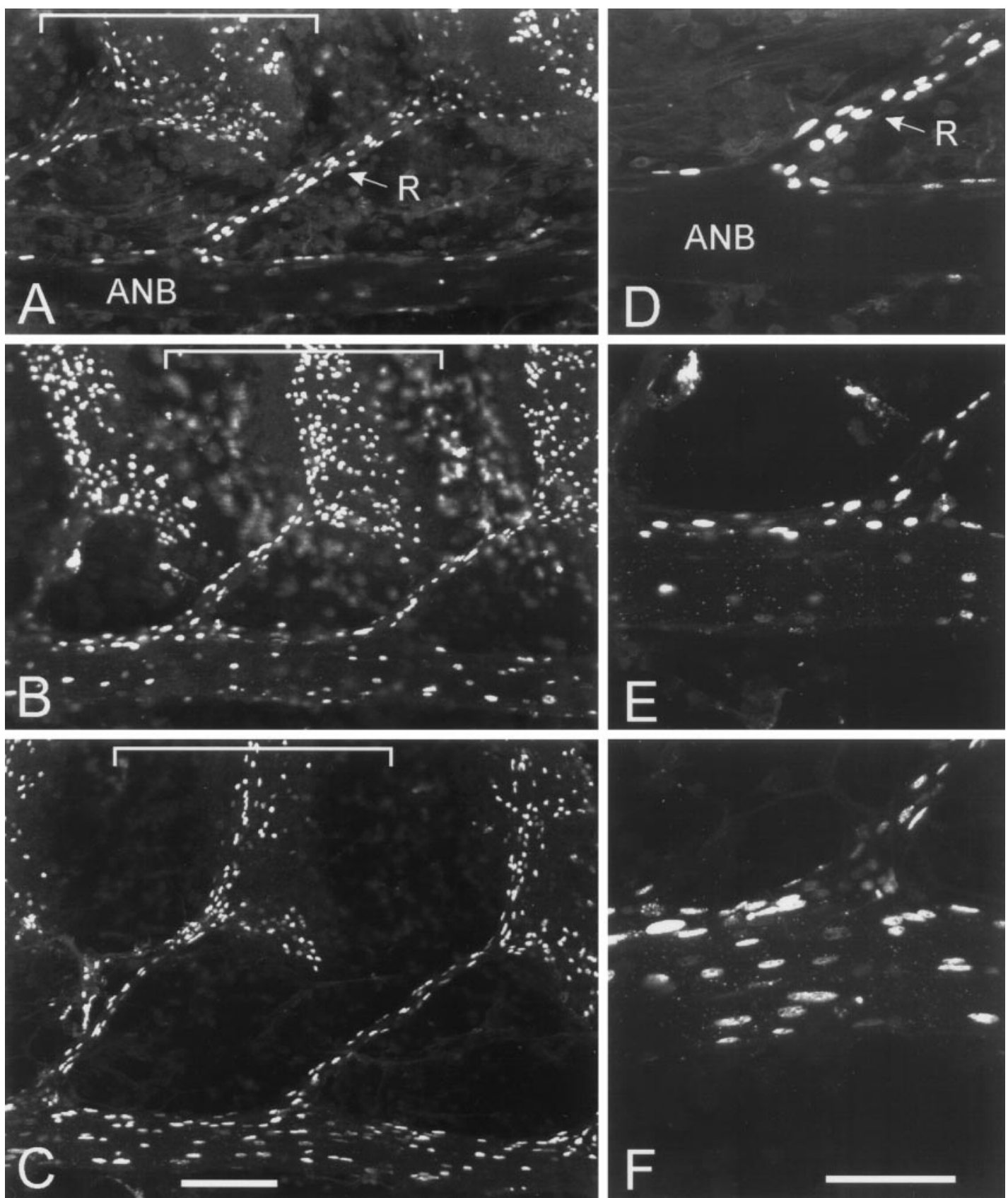

Figure 7. BrdU-labeled glial cells in the antennal portion of the antennal nerve. One of the two main branches of the antennal nerve $(A N B)$, nerve rootlets $(R)$, and sensory epithelium shown in one-half of an opened antenna at stage $3(A)$, stage $4(B)$, and stage $5(C)$. The nerve branch is shown at higher magnification in $D$ (stage 3), $E$ (stage 4 ), and $F$ (stage 5). The white brackets in $A, B$, and $C$ indicate the borders of one hemisegment. Scale bars: shown in $C$ for $A-C, 100 \mu \mathrm{m}$; shown in $F$ for $D-F, 25 \mu \mathrm{m}$.

mechanosensory axons. The number of BrdU-labeled cells in the AN branch increased at stage 5 , whereas the number of labeled cells in the epithelium appeared to decrease (Fig. $7 C, F$ ), and by stage 7, BrdU-labeled glial cells no longer were found in either the epithelium or the AN branches (data not shown).

\section{Influence of sensory axons and the antennal lobe on the development of glia in the sorting zone and the antennal nerve}

If the hypothesis that the glial cells populating the sorting zone are generated in the AL is correct, removal of the AL should result in the absence of an accumulation of glial cells resembling a sorting zone at the base of the AN. In addition, if the glia in the peripheral part of the AN arise in the antenna, removal of the AL should result in an AN containing the typical peripheral type of glia increasingly far from the antenna as development proceeds. Previous experiments have shown that the antennal sensory epithelium develops normally without contact between the sensory axons and their central targets and that, in the absence of brain tissue, ingrowing ANs form neuromas within the head (Sanes et al., 1976). To remove the axons' CNS target, we removed brains of moths at late stage 2 (before ORC axons enter the AL) and examined the distribution of glial cells along the $\mathrm{AN}$ and in its 


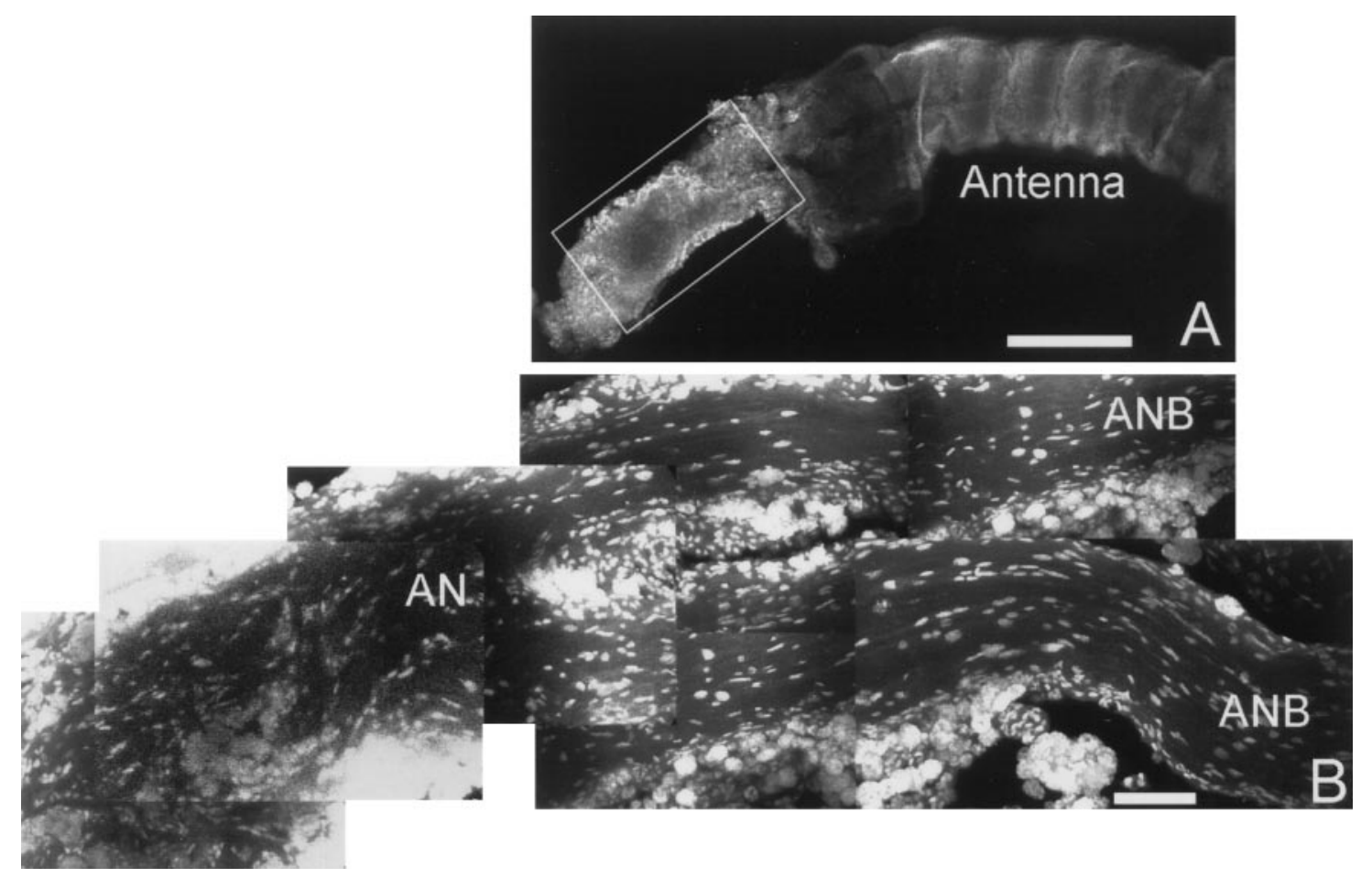

Figure 8. Development of glial cells in the intracranial portion of an antennal nerve growing in the absence of the brain. $A$, Proximal portion of the antenna (Antenna) and its antennal nerve that grew into the head cavity (stage 7). B. Higher magnification of the intracranial portion of the antennal nerve (boxed area in $A$ ) showing the two nerve branches $(A N B)$ and a neuroma-like nerve ending containing glial cells (labeled with propidium iodide). Scale bars: $A, 200 \mu \mathrm{m} ; B, 50 \mu \mathrm{m}$.

intracranial neuroma (Fig. 8). At stage 7, the peripheral ANs contained glial cells with elongated nuclei that were distributed similarly to the arrangement of peripheral nerve glia found in the ANs of normal moths at this stage; however, the typical distribution of glial cells along the middle of the AN was absent, and in the entrance region of the neuromas or within the neuromas, we never found an accumulation of glial cells resembling the distribution of glia in either the sorting zone or the AL neuropil. This supports the hypothesis that sorting zone glial cells are generated centrally.

As described earlier, during normal development, glial cells in the entry area of the AL begin to proliferate immediately after the first ORC axons arrive at the AL, suggesting that the formation of the sorting zone is triggered by sensory axons. To test this, we studied the distribution and proliferation pattern of glial cells at the lateral edge of the AL in the absence of ORC axons or in the presence of only a small number of ORC axons. This was achieved by complete or partial removal of the antenna. Previous studies have shown that after complete deantennation, the neuropil-related glial cells within the AL continue to proliferate at about the same rate as in normal ALs (Oland and Tolbert, 1987). Our current results from BrdU-labeled preparations confirmed this at stage 5 (Fig. 9A) and also showed that the labeled glial cells were evenly distributed around the perimeter of the AL without increased proliferation in the region where normally the AN would enter the AL (Fig. 9, arrow). After partial deafferentation, however, when only a small number of sensory axons from a few proximal annuli on the flagellum (approximately 5 of 80 annuli) grew into the AL, the lateral glial border became disrupted, and a small accumulation of glial cells formed in the entrance region of the $\mathrm{AN}$ (Fig. 9B,C). In addition, the glial cells in this lateral region as well as in adjacent regions of neuropil appeared to have more elaborated processes than those in completely deafferented ALs (Fig. 9B). The results indicate that ingrowth of sensory axons from the antenna induces proliferation and a change in the morphology of glial cells in the sorting zone that forms near the entrance region of the AL.

\section{DISCUSSION}

Our interest in the sorting zone in the proximal AN of Manduca was driven by the abruptness of transition from glia-poor to glia-rich nerve and the sudden change in axonal behavior as axons enter the zone (Fig. 10). Given the potential experimental advantage conveyed by the length of the nerve in Manduca, the sorting zone offers an opportunity to explore the mechanisms that determine how ORC axons become associated with other ORC axons heading to the same glomerular targets. In the current study, we found that glial cells in the sorting zone do influence the sorting process, and we therefore focused our attention on the proliferation patterns of the glial cells that inhabit the zone. Our goals were to determine the basic construction plan for the sorting zone and whether the glia arise centrally or peripherally and whether their presence depends on the receptor axons.

\section{Possible role of glial cells in sorting of olfactory receptor axons}

Several observations suggest that regrouping of ORC axons in Manduca depends on signaling between the axons and the glia in the sorting zone. First, ORC axons change their trajectories and lose their neighbor associations as soon as they encounter glial cells in the sorting zone. Second, with a reduced number of glial cells in the sorting zone as well as in the AL, fasciclin IIimmunoreactive ORC axons leave the sorting zone without fasciculating, and many MFas $\mathrm{II}^{+}$axons subsequently grow beyond 

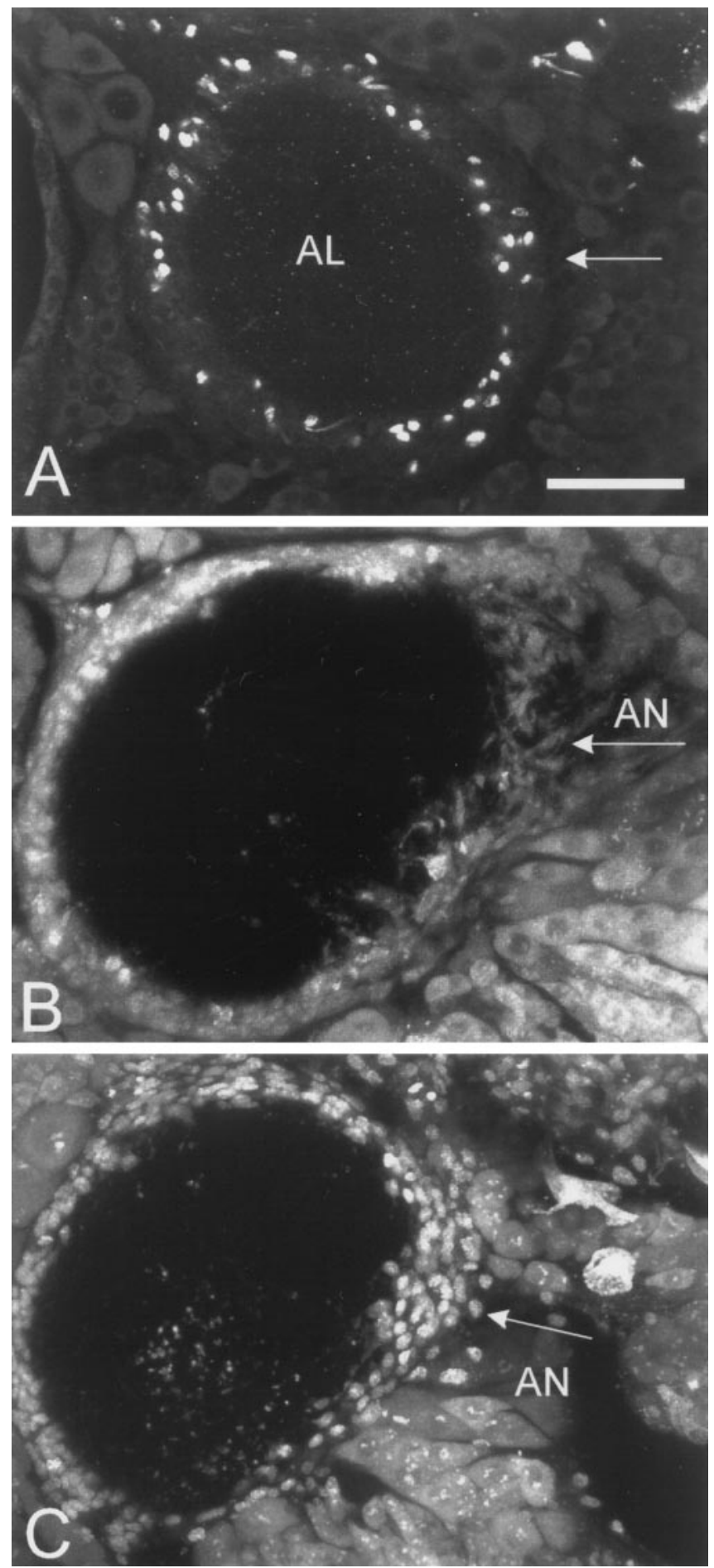

Figure 9. Development of the sorting zone after complete or partial deafferentation. $A$, Proliferation of glial cells in the antennal lobes $(A L)$ at stage 5 after complete deafferentation. The ALs contain BrdU-labeled glial nuclei, indicating proliferation of neuropil-associated glia in the absence of sensory innervation. No accumulation of glial cells or increased proliferation can be seen in the region where normally the antennal nerve $(A N)$ would enter the $A L$ (white arrow). $B, C$, ALs at stage 5 after partial deafferentation (ingrowth of sensory axons from approximately five segments on the antennal flagellum). Glial cells (labeled with propidium iodide) in the entrance region of the AN have proliferated more than those in other regions of the $A L$ (white arrow in $C$; treatment with high levels of RNase) and show more elaborate processes (white arrow in $B$; treatment with lower levels of RNase to highlight glial processes). Scale bar: shown in $A$ for $A-C, 50 \mu \mathrm{m}$. their normal targets [Higgins et al. (1998) and this study]. Third, the projection pattern of macroglomerular complex-specific axons growing into AN neuromas indicates that the axons do not fasciculate or become segregated within the neuromas (Rössler et al., 1999), which lack any accumulation of glia reminiscent of a sorting zone. Finally, ORC axon growth cones in the sorting zone often are closely apposed to glial cells (Oland et al., 1998a) and are sometimes virtually enwrapped by glial processes. In vertebrates, peripheral ensheathing glia and astrocytes of central origin form a distinct pattern in the nerve layer and marginal zone of the developing olfactory bulb (Doucette, 1989; Valverde et al., 1992), in a region where ingrowing ORC axons defasciculate (Whitesides and LaMantia, 1996). Thus, in the vertebrate olfactory system, too, glial cells could play a role in regrouping axons. Interactions of axons with glial cells also has been postulated in the visual and auditory systems of vertebrates. A palisade of radial glia proximal to the midline of the optic chiasm appears to contain cues for rearrangement of axons (Maggs and Scholes, 1986; Marcus et al., 1995; Wang et al., 1995), and BrunsoBechtold and Henkel (1996) have suggested that glial cells at the midline of the auditory hindbrain provide guidance cues for developing auditory fibers.

The mechanism of the proposed signaling interaction among axons and glial cells in the sorting zone of Manduca is as yet unknown. No junctional specializations or other morphological substrates for interaction between the ORC axons and glia have been detected at the ultrastructural level. The high density of glial cells in the sorting zone might simply provide a physical obstacle that impedes or slows the growth of axons, thus increasing the opportunity to find appropriate partners for fasciculation. Alternatively, either membrane-bound or diffusible molecules associated with glial cells in the sorting zone may influence the behavior of all or some ORC axons. Tenascin-like molecules, shown to be associated with glial cells in the AL during axon ingrowth and glomerulus construction (Krull et al., 1994a,b), could alter, for example, the balance between adhesion and defasciculation of axons and thus allow axonal sorting. An attractive hypothesis is that physical or chemical interaction, or both, with glia in the sorting zone directly affects the pattern of expression of cell adhesion molecules in the axonal membranes. In at least the MFas II ${ }^{+}$subset of axons (Higgins et al., 1998), cell adhesion molecules may be involved in fasciculation. Among a number of cell adhesion molecules shown to be present at developmentally relevant times in vertebrates (Miragall et al., 1989; Yoshihara et al., 1995; Whitesides and LaMantia, 1996), the cell adhesion molecule OCAM, related to both NCAM and fasciclin II, is hypothesized to play a direct role in fasciculation of ORC axons (Yoshihara et al., 1997).

\section{The source of glial cells in the sorting zone and the peripheral antennal nerve}

A rudimentary sorting zone defined by glial cells is present from the beginning of ORC axon arrival, and the glial proliferation pattern within the sorting zone parallels that of the neuropilassociated glia (Oland and Tolbert, 1987; Kirschenbaum et al., 1995). The temporally defined distribution and proliferation patterns of glia in the sorting zone and the peripheral AN strongly suggest that the glia in the sorting zone arise from the glial population in the AL, whereas glia in the remainder of the nerve arise peripherally. The distribution and proliferation pattern of glial cells in the antenna indicate that glial cells that are present in the peripheral $\mathrm{AN}$ at later stages are born in the antenna and 


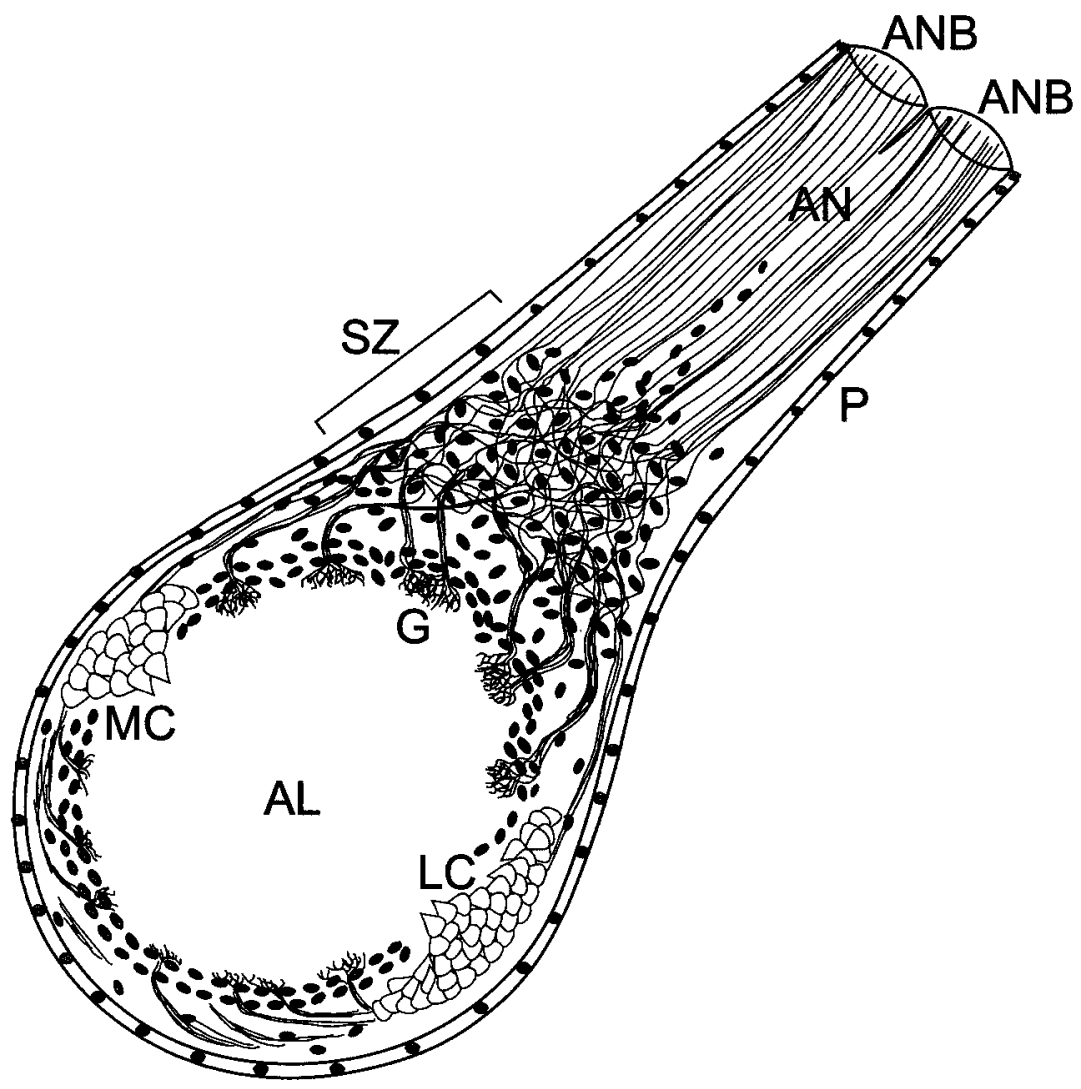

Figure 10. Schematic summary of sorting zone at stage 5 . In the antennal nerve $(A N)$, axons from olfactory receptor cells in the antenna maintain topographic relationships with axons from neighboring receptor cells until they reach the sorting zone $(S Z)$. In the SZ, the axons encounter a dense cluster of glial cells of CNS origin and abruptly begin to curve and turn. They emerge from the SZ in fascicles, which run in a nerve layer outside the neuropil of the antennal lobe $(A L)$ before crossing through a layer of neuropil-associated glial cells to terminate in developing glomeruli $(G)$. $A N B$, Two branches of the peripheral antennal nerve; $L C$ and $M C$, lateral and medial cell group of $A L$ neurons in clusters outside the neuropil; $P$, perineurial sheath. subsequently migrate down the nerve rootlets into the AN [in a manner reminiscent of the migration of non-neuronal cells with ingrowing ORC axons in the developing mouse (Farbman and Squinto, 1985)]. The fact that glial cells are present in the antennal portion of the AN at stages 4 and 5 but do not appear in the intracranial portion of the AN before the end of stage 6 indicates that the migration of glial cells lags behind the outgrowing tips of ORC axons. The function of the peripheral glia in the mature AN is probably to ensheathe axons, as described by Sanes and Hildebrand (1976).

Three pieces of evidence suggest that sorting-zone glial cells (and glia extending along the middle of the proximal AN) are generated by a central source of glia, most likely arising from the neuropil-associated glia near the lateral edge of the AL. (1) A sorting zone defined by both axonal behavior and glial presence is present several stages before the rest of the AN contains glia. (2) Although the density of glial cells in the sorting zone and the size of the zone do increase between stages 3 and 7, the region remains quite restricted. At the same time, the remainder of the AN gradually becomes populated with glia from the antenna in a distal to proximal direction. (3) No accumulation of glial cells resembling the arrangement of those in the sorting zone was found at the blind endings of ANs in debrained moths. Note that the generation and migration of the glial cells ensheathing the axons in the AN must be independent of contact of the AN with its central target, because the antenna and AN develop normally even in the absence of the AL (Sanes et al., 1976). We cannot rule out a contribution of perineurial glia to the sorting zone but consider the possibility remote because perineurial cells have been shown, at least in crickets, to be derived from mesodermal tissue (Edwards et al., 1993; Edwards and Tolbert, 1998). The data also indicate that the production of glial cells in the sorting zone is triggered by ingrowth of the first ORC axons. Not only is glial cell proliferation increased at the lateral edge of the AL within $1 \mathrm{~d}$ of the arrival of the first axons, but in the absence of axons, there is no increase in proliferation in this region. A few axons apparently are sufficient to induce the proliferation necessary to begin construction of the sorting zone. In earlier studies of glial cell proliferation in the AL (Oland and Tolbert, 1987), the sorting zone glia would have been excluded from counts of the number of dividing glia because they do not lie adjacent to the neuropil but rather are within the AN.

\section{Possible role of the sorting zone in chemotopic mapping of ORC axons in the developing antennal lobe}

Our results together with other recent findings suggest that the generation of a chemotopic map of ORC axons in the developing $\mathrm{AL}$ of Manduca requires several steps, some of which involve intercellular communication among ORC axons and glial cells. The following, partly hypothetical, sequence of events represents our current working model. (1) Early ORC axons grow toward the AL using guidance cues provided by the pupal nerve and possibly by a diffusible factor released by the AL (Oland et al., 1998a,b). (2) As soon as they reach the lateral border of the AL, the ORC axons induce glial proliferation and establishment of the sorting zone. (3) ORC axon-glia interactions within the sorting zone promote disassociation of topographically organized ORC axon bundles. (4) Subsequent interactions among ORC axons result in chemotopic fasciculation of ORC axons heading to the same glomerulus. (5) Cues within the AL guide ORC axons to their correct targets (Kent et al., 1999; Rössler et al., 1999). (6) After the initial pathfinding of early ingrowing ORC axons, "follower" axons (ingrowth lasts from stage 3 to stage 9) can 
fasciculate with their chemotopic "partners" in the sorting region and follow their projections to the correct glomerulus.

Our results suggest that, in addition to playing a role in the formation and stabilization of glomeruli, glial cells appear to have an important function in the sorting zone in the establishment of a chemotopic organization within the primary olfactory centers. Future investigations using live-cell imaging techniques and molecular tools will focus on the dynamics and molecular nature of signals underlying axon-glia interactions, aiming toward an understanding of the complex roles of glia in the development of the olfactory pathway.

\section{REFERENCES}

Baumann PM, Oland LA, Tolbert LP (1996) Glial cells stabilize axonal protoglomeruli in the developing olfactory lobe of the moth Manduca sexta. J Comp Neurol 373:118-128.

Brunso-Bechtold JK, Henkel CK (1996) Axon decussation and midline glia in the developing ferret auditory hindbrain. Physiol Brain Res 108:165-181.

Christensen TA, Harrow ID, Cuzzocrea C, Randolph PW, Hildebrand JG (1995) Distinct projections of two populations of olfactory receptor axons in the antennal lobe of the sphinx moth Manduca sexta. Chem Senses 20:313-323.

Clyne PJ, Warr CG, Freeman MR, Lessing D, Kim J, Carlson JR (1999a) A novel family of divergent seven-transmembrane proteins: candidate odorant receptors in Drosophila. Neuron 22:327-338.

Clyne PJ, Certel SJ, de Bruyne M, Zaslavsky L, Johnson WA, Carlson JR (1999b) The odor specificities of a subset of olfactory receptor neurons are governed by Acj6, a POU-domain transcription factor. Neuron 22:339-347.

Doucette R (1984) The glial cells in the nerve fiber layer of the rat olfactory bulb. Anat Rec 210:385-391.

Doucette R (1989) Development of the nerve fiber layer in the olfactory bulb of mouse embryos. J Comp Neurol 285:514-527.

Edwards JS, Tolbert LP (1998) Insect neuroglia. In: Microscopic anatomy of invertebrates, Vol 11B: Insecta (Harrison FW, Locke M, eds), pp 449-466. New York: Wiley-Liss

Edwards JS, Swales LS, Bate M (1993) The differentiation between neuroglia and connective tissue sheath in insect ganglia revisited: the neural lamella and perineurial sheath cells are absent in a mesodermless mutant of Drosophila. J Comp Neurol 333:301-308.

Farbman AI, Squinto LM (1985) Early development of olfactory receptor cell axons. Brain Res 351:205-213.

Gratzner N (1982) Monoclonal antibody to 5-bromo- and 5-iodo-deoxyuridine: a new reagent for detection of DNA replication. Science 218:474-475.

Higgins MR, Eckhold PA, Gibson NJ, Oland LA, Copenhaver PF, Tolbert LP (1998) Cues guiding olfactory axons to their targets in the brain of Manduca sexta. Soc Neurosci Abstr 24:1142.

Hildebrand JG (1996) Olfactory control of behavior in moths: central processing of odor information and the functional significance of olfactory glomeruli. J Comp Physiol [A] 178:5-19.

Kent KS, Harrow ID, Quartararo P, Hildebrand JG (1986) An accessory olfactory pathway in Lepidoptera; the labial pit organ and its central projections in Manduca sexta and certain other sphinx and silk moths. Cell Tissue Res 245:237-245.

Kent KS, Oland LA, Hildebrand JG (1999) Development of the labial pit organ glomerulus in the antennal lobe of the moth, Manduca sexta: the role of afferent projections in the formation of identifiable olfactory glomeruli. J Neurobiol 40:28-44.

Kirschenbaum SR, Higgins MR, Tveten M, Tolbert LP (1995) 20Hydroxyecdysone stimulates proliferation of glial cells in the developing brain of the moth Manduca sexta. J Neurobiol 28:234-247.

Krull CE, Morton DB, Faissner A, Schachner M, Tolbert LP (1994a) Spatiotemporal pattern of expression of tenascin-like molecules in the developing olfactory system. J Neurobiol 15:515-534.

Krull CE, Oland LA, Faissner A, Schachner M, Tolbert LP (1994b) In vitro analyses of neurite outgrowth indicate a potential role for tenascin-like molecules in the development of insect olfactory glomeruli. J Neurobiol 25:989-1004.

Maggs A, Scholes J (1986) Glial domains and nerve fiber patterns in the fish retinotectal pathway. J Neurosci 6:424-438.

Marcus RC, Blaseski R, Godement P, Mason CA (1995) Retinal axons diverge in the optic chiasm: uncrossed axons diverge from crossed axons within a midline glial specialization. J Neurosci 15:3716-3729.

Marin-Padilla M, Amieva MR (1989) Early neurogenesis of the mouse olfactory nerve: Golgi and electron microscopic studies. J Comp Neurol 288:339-352.

Miragall F, Kadmon G, Schachner M (1989) Expression of L1 and NCAM cell adhesion molecules during development of mouse olfactory system. Dev Biol 135:272-286.

Mombaerts P, Wang F, Dulac C, Chao SK, Nemes A, Mendelsohn M, Edmondson J, Axel R (1996) Visualizing an olfactory sensory map. Cell 87:675-686.

Nardi JB (1992) Dynamic expression of a cell surface protein during rearrangement of epithelial cells in the Manduca wing monolayer. Dev Biol 152:161-171.

Oland LA, Tolbert LP (1987) Glial patterns during early development of antennal lobes of Manduca sexta: a comparison between normal lobes and lobes deprived of antennal axons. J Comp Neurol 255:196-207.

Oland LA, Tolbert LP (1989) Patterns of glial proliferation during formation of olfactory glomeruli in an insect. Glia 2:10-24.

Oland LA, Tolbert LP (1996) Multiple factors shape development of olfactory glomeruli: insights from an insect model system. J Neurobiol 30:92-109.

Oland LA, Orr G, Tolbert LP (1990) Construction of a protoglomerular template by olfactory axons initiates the formation of olfactory glomeruli in the insect brain. J Neurosci 10:2096-2112.

Oland LA, Pott WM, Higgins MR, Tolbert LP (1998a) Targeted ingrowth and glial relationships of olfactory receptor axons in the primary olfactory pathway of an insect. J Comp Neurol 398:119-138.

Oland LA, Pott WM, Tolbert LP (1998b) Guidance and sorting of olfactory receptor axons in the moth Manduca sexta. Soc Neurosci Abstr 24:1142.

Oland LA, Marrero HG, Burger I (1999a) Glial cells in the developing and adult olfactory lobe of the moth Manduca sexta. Cell Tissue Res, in press.

Oland LA, Rössler W, Hildebrand JG, Tolbert LP (1999b) Origin of glial cells in the axon sorting zone in the olfactory pathway of the moth Manduca sexta. Soc Neurosci Abstr 25:752.

Raisman G (1985) Specialized neuroglial arrangement may explain the capacity of vomeronasal axons to reinnervate central neurons. Neuroscience 14:237-254.

Ressler KJ, Sullivan SL, Buck LB (1994) Information coding in the olfactory system: evidence for a stereotyped and highly organized epitope map in the olfactory bulb. Cell 79:1245-1255.

Riddle DR, Oakley B (1991) Evaluation of projection patterns in the primary olfactory system of rainbow trout. J Neurosci 11:3752-3762.

Rössler W, Tolbert LP, Hildebrand JG (1998) Early formation of sexually dimorphic glomeruli in the developing olfactory system of the brain of the moth Manduca sexta. J Comp Neurol 396:415-428.

Rössler W, Randolph PW, Tolbert LP, Hildebrand JG (1999) Axons of olfactory receptor cells of transsexually grafted antennae induce development of sexually dimorphic glomeruli in Manduca sexta. J Neurobiol 38:521-541.

Sanes JR, Hildebrand JG (1976) Structure and development of antennae in a moth, Manduca sexta. Dev Biol 51:282-299.

Sanes JR, Hildebrand JG, Prescott DJ (1976) Differentiation of insect sensory neurons in the absence of their normal synaptic targets. Dev Biol 52:121-127.

Schneiderman AM (1984) Postembryonic development of a sexually dimorphic sensory pathway in the central nervous system of the sphinx moth, Manduca sexta. PhD thesis. Harvard University.

Tolbert LP, Hildebrand JG (1981) Organization and synaptic ultrastructure of glomeruli in the antennal lobes of the moth Manduca sexta: a study using thin sections and freeze fracture. Proc R Soc Lond B Biol Sci 213:279-301.

Tolbert LP, Sirianni PA (1990) Requirement for olfactory axons in the induction and stabilization of olfactory glomeruli in an insect. J Comp Neurol 298:69-92.

Tolbert LP, Matsumoto SG, Hildebrand JG (1983) Development of synapses in the antennal lobes of the moth Manduca sexta during metamorphosis. J Neurosci 3:1158-1175.

Valverde F, Santacana M, Heredia M (1992) Formation of an olfactory glomerulus: morphological aspects of development and organization. Neuroscience 49:255-275.

Vassar R, Chao SK, Sitcheran R, Nunez JM, Vosshall LB, Axel R (1994) 
Topographic organization of sensory projections to the olfactory bulb. Cell 79:981-991.

Vosshall LB, Amrein H, Morozov PS, Rzhetsky A, Axel R (1999) A spatial map of olfactory receptor expression in the Drosophila antenna. Cell 96:725-736.

Wang F, Nemes A, Mendelsohn M, Axel R (1998) Odorant receptors govern the formation of a precise topographic map. Cell 93:47-60.

Wang LC, Dani J, Godement P, Marcus RC, Mason CA (1995) Crossed and uncrossed retinal axons respond differently to cells of the optic chiasm midline in vitro. Neuron 15:1349-1364.

Whitesides JG, LaMantia AS (1996) Differential adhesion and the initial assembly of the mammalian olfactory nerve. J Comp Neurol 373:240-254.

Yoshihara Y, Kawasaki M, Tamada A, Nagata S, Kagamiyama H, Mori K (1995) Overlapping and differential expression of BIG-2, BIG-1, TAG-1, and F3: four members of an axon-associated cell adhesion molecule subgroup of the immunoglobulin superfamily. J Neurobiol 28:51-69.

Yoshihara Y, Kawasaki M, Tamada A, Fujita H, Hayashi H, Kagamiyama H, Mori K (1997) OCAM: a new member of the neural cell adhesion molecule family related to zone-to-zone projection of olfactory and vomeronasal axons. J Neurosci 17:5830-5842. 